\section{Revista}

Ibero-Americana

de Estratégıa

\title{
A ESTRATÉGIA DE GESTÃo DE PESSOAS COMO FERRAMENTA DO DESENVOLVIMENTO ORGANIZACIONAL
}

PEOPLE MANAGEMENT AS A STRATEGIC TOOL FOR ORGANIZATIONAL DEVELOPMENT

\section{LA ESTRATEGIA DE LA GESTIÓN DE PERSONAS COMO UNA HERRAMIENTA ESTRATÉGICA PARA EL DESARROLLO ORGANIZACIONAL}

Nildes Raimunda Pitombo Leite

Doutora em Administração pela Universidade de São Paulo - USP

Professora e pesquisadora do Programa de Mestrado e Doutorado da Universidade Nove de Julho PMDA/UNINOVE

E-mail: nildesrpl@uninove.br (Brasil)

\section{Lindolfo Galvão de Albuquerque}

Doutor em Administração pela Universidade de São Paulo - USP

Professor da Universidade de São Paulo - USP

E-mail: Igdalbuq@usp.br (Brasil) 
A Estratégia de Gestão de Pessoas como Ferramenta do Desenvolvimento Organizacional

\title{
A ESTRATÉGIA dE GESTÃo de PESSOAS COMO FERRAMENTA DO \\ DESENVOLVIMENTO ORGANIZACIONAL
}

\section{RESUMO}

Este artigo objetiva compreender e elucidar as relações entre estratégia de gestão de pessoas, estratégia de mudança e desenvolvimento organizacional, no sentido de verificar suas confluências e sua interação dinâmica. Trata-se de um estudo exploratório, de abordagem qualitativa, com a utilização do método de estudo de caso, realizado em uma organização multinacional voltada para o desenvolvimento e a produção de produtos de carbono e grafita. Coletaram-se os dados primários por meio de realização de entrevistas envolvendo-se, nessa coleta, cinco pessoas do grupo de topo, seis do gerencial, quatro do marketing/comercial, quatro do staff e sete representantes dos grupos operacionais e administrativos, constituindo-se, posteriormente, cinco grupos de foco. Os dados secundários foram levantados dos documentos organizacionais. A interpretação dos dados primários se deu a partir da análise de conteúdo. Verificou-se, a partir da análise de conteúdo das entrevistas e dos grupos focais, que a estratégia de gestão de pessoas pôde ser utilizada como instrumento de desenvolvimento organizacional na organização investigada.

Palavras-chave: Gestão Estratégica de Pessoas; Estratégia de Mudança; Desenvolvimento Organizacional.

\section{PEOPLE MANAGEMENT AS A STRATEGIC TOOL FOR ORGANIZATIONAL DEVELOPMENT}

\begin{abstract}
This article investigates the confluences and the dynamic interactions among people management, change strategy, and organizational development. It reports an exploratory, qualitative study: a case study involving a multinational company focused on the development and manufacture of carbon and graphite products. Primary data was collected through interviews involving five top executives, six managers, four sales/marketing persons, four staff, and seven representatives from operations. Secondary data was obtained from company documents. Based on content analysis from the interviews, it was concluded that the management of people in this organization was used as a tool for organizational development.
\end{abstract}

Keywords: Strategic Management of People; Change Strategy; Organizational Development.

Revista Ibero-Americana de Estratégia - RIAE, São Paulo, v. 9, n. 1, p. 32-55, jan./abr. 2010. 
Nildes Raimunda Pitombo Leite \& Lindolfo Galvão de Albuquerque

\section{LA ESTRATEGIA DE LA GESTIÓN DE PERSONAS COMO UNA HERRAMIENTA ESTRATÉGICA PARA EL DESARROLLO ORGANIZACIONAL}

\section{RESUMEN}

Este artículo tiene como objetivo comprender y dilucidar las relaciones entre la estrategia de la gestión de personas, la estrategia del cambio y desarrollo organizacional, en el sentido de verificar sus confluencias y su interacción dinámica. Se trata de un estudio exploratorio, con un enfoque cualitativo, con la utilización del método de estudio de caso, realizado en una empresa multinacional, con enfoque en el desarrollo y fabricación de productos de carbono y grafito. Los datos primarios fueron recolectados a través de entrevistas a cinco altos ejecutivos, seis directores, cuatro de marketing y comercialización, cuatro de personal y siete representantes de los grupos operacionales y administrativos, constituyéndose posteriormente cinco grupos de enfoque. Los datos secundarios se obtuvieron de documentos de la empresa. La interpretación de los datos primarios fue realizada a partir del análisis de contenido. Se verificó a partir de este análisis y los grupos de enfoque, que la estrategia de la gestión de personas en esta organización puede ser utilizada como una herramienta para el desarrollo de la organización.

Palabras-clave: Gestión Estratégica de Personas; Estrategia del Cambio; Desarrollo Organizacional. 
A Estratégia de Gestão de Pessoas como Ferramenta do Desenvolvimento Organizacional

\section{INTRODUÇÃO}

O período de transformações sociais que caracterizou a década de 1960 e provocou mudanças significativas no comportamento das pessoas, principalmente nos segmentos mais jovens da sociedade, também foi sentido no ambiente organizacional e na administração das organizações. O contexto do mundo corporativo contemporâneo demanda discutir e compreender os processos pelos quais ocorre o desenvolvimento das organizações. Para tanto, a definição de estratégia oferece uma linha, uma conduta a seguir para as organizações e, tanto quanto por sua presença ou por sua ausência, podem ser vitais.

$\mathrm{Na}$ teoria organizacional a origem de estratégia está representada pela metáfora militar, que transfere para o concorrente a figura do adversário e, para o mercado, a figura de campo de batalha (Hatch, 1997). Na prática organizacional, Wright, Kroll \& Parnell (1998) salientaram que a estratégia refere-se ao que a alta administração planeja para alcançar resultados, em consonância com a missão e os objetivos gerais da organização.

No que tange à gestão estratégica de pessoas, Martín-Alcazár, Romero-Fernandez e Sanches-Gardey (2008) indicaram que a gestão de pessoas abrange políticas, práticas e filosofias globais, envolvendo a força de trabalho e as questões sociais, constituintes dos elementos centrais da estratégia. Do mesmo modo, Lengnick-Hall, M. L.; Lengnick-Hall, C. A.; Andrad \& Drake (2009) sugeriram que as ideias acerca do tema remontam à década de 1920, nos Estados Unidos, nas quais, políticas e práticas de gestão de pessoas eram discutidas por economistas e acadêmicos das relações industriais.

Por sua vez, o desenvolvimento organizacional foi reconhecido inicialmente como uma estratégia ou um programa de ação voltado para gerenciar o processo de mudança organizacional. A palavra-chave no desenvolvimento organizacional nesse contexto era, portanto, mudança.

Ao definir o que é desenvolvimento organizacional e elucidar a sua necessidade, Bennis (1972) o fez com tal propriedade que se tornou fácil depreender que se trata de um processo e necessita de tempo para ser implantado, acompanhado, consolidado, verticalizado e institucionalizado.

Ainda em 1972 Motta declarou que o desenvolvimento organizacional ganhou o significado, com o qual se apresentava, somente no momento em que a teoria das organizações foi submetida ao tratamento sistêmico, responsável por reconciliar o estrutural com o comportamental. Motta (1972) atribuiu a Bennis o papel altamente significativo, nesse sentido, imputado ao tema.

Neste artigo, procurou-se compreender as relações entre estratégia de gestão de pessoas, estratégia de mudança e desenvolvimento organizacional, a fim de explicar a interação dinâmica 
que ocorre no fenômeno de desenvolvimento de uma organização multinacional do segmento de carbono e grafita. Com isso, buscou-se também responder à questão de como a estratégia de gestão de pessoas pode ser utilizada como ferramenta para o desenvolvimento organizacional.

No intento de nortear o percurso de investigação, a primeira parte deste artigo traz uma fundamentação teórica breve sobre a relação entre estratégia de gestão de pessoas, estratégia de mudança e desenvolvimento organizacional. A segunda parte relata o estudo de caso em uma organização multinacional do segmento de carbono e grafita, em que se buscou analisar o processo de interação dinâmica entre estratégia de gestão de pessoas, estratégia de mudança e desenvolvimento organizacional, por meio da descrição e análise desse processo implementado pela via da gestão estratégica de pessoas. Para resguardar a identidade da organização em estudo, ela será aqui denominada de OM Brasil.

Este trabalho de pesquisa justificou-se por duas razões: gestão de pessoas, estratégia de mudança e desenvolvimento organizacional são temáticas recorrentes; mudança de estratégia de controle para estratégia de comprometimento das pessoas com os objetivos organizacionais mostrase como necessidade imperativa nas organizações contemporâneas.

\section{A ESTRATÉGIA DE GESTÃO DE PESSOAS}

No contexto da gestão de pessoas, em 1987 Albuquerque fez pesquisa na realidade nacional, na qual enfocava a importância e a necessidade de pensar recursos humanos no nível organizacional estratégico. Para tal, o perfil traçado envolvia: formulação da estratégia organizacional; definição da filosofia gerencial; planejamento do processo de desenvolvimento organizacional; posicionamento da organização perante o ambiente externo. Tudo isso implicava necessidade de migração da administração de recursos humanos para a administração estratégica de recursos humanos.

Para Fischer (1998), o termo gestão de pessoas procurava ressaltar o caráter da ação: a gestão e seu foco de atenção: as pessoas. O caráter estratégico dos sistemas de gestão de recursos humanos surgiu na década de 1980, como novo critério de efetividade.

As razões que envolviam a migração da administração de recursos humanos para a administração estratégica de recursos humanos, explicitadas por Marras (2000), estavam atreladas a: globalização dos mercados e seus desdobramentos nas organizações; mudanças na filosofia de vida; mudanças de paradigmas tecnológicos que modificam, substancialmente, o rumo dos resultados organizacionais e o perfil cultural da organização. Essas razões, indubitavelmente devem ser cotejadas pela alta administração nos momentos de planejamento.

Revista Ibero-Americana de Estratégia - RIAE, São Paulo, v. 9, n. 1, p. 32-55, jan./abr. 2010. 
A Estratégia de Gestão de Pessoas como Ferramenta do Desenvolvimento Organizacional

A variedade de abordagens conceituais na definição estratégica, que englobasse os diferentes sentidos, levou Albuquerque (2002) a conceituar estratégia, para fins de análise, como a formulação da missão e dos objetivos da organização, bem como de políticas e planos de ação para alcançá-los, considerando-se os impactos das forças do ambiente e a competição. Torna-se relevante relembrar que as políticas tomam por base as estratégias estabelecidas, devendo, portanto, estar de acordo com elas (Fischmann \& Almeida, 1990).

As atividades de gestão de pessoas cumprem seu papel para captar, reter e desenvolver talentos capazes de fazer o diferencial das organizações. Encontram-se nesse bojo, conforme explicitados por Casado (2007), os procedimentos de recrutamento, as técnicas de seleção, as políticas de compensação, as formas de relacionamento com os representantes de empregados, os modelos de treinamento e desenvolvimento e os planos para progressão na carreira. Muitas vezes, conforme alertado pela autora, essas ferramentas e práticas de gestão de pessoas confundem-se com as próprias divisões funcionais e deixam de receber o devido cuidado de práticos da administração, que nem sempre conhecem os fundamentos conceituais que norteiam essas ações.

Por seu turno, a estratégia de gestão de pessoas cuida de descrever a orientação da organização, no que se refere à gestão do fator humano. Para tanto, proporciona coesão ao conjunto de práticas por meio das quais essa gestão é implementada. Da mesma forma, as políticas cuidam de descrever a coordenação dessas práticas com vistas ao alcance dos objetivos ligados à força de trabalho (Martín-Alcázar, Romero-Fernández \& Sanchez-Gardey, 2005).

São diversas as implicações sugeridas pela evolução das ideias em gestão estratégica de pessoas para a prática organizacional, destacando-se, para Mascarenhas (2008): as possibilidades de desenvolvimento das competências dos agentes envolvidos com a gestão de pessoas, incluindo profissionais de recursos humanos e líderes de equipes; entrelaçamento entre abordagens desenvolvidas em campos acadêmicos distintos.

Oriunda de tal entrelaçamento, a gestão de pessoas sob a concepção holística foi indicada por Medeiros (1999), ao reiterar e relembrar o antigo tripé de habilidades requeridas para o exercício dessa gestão, o qual inclui: sensibilidade e empatia para lidar com as pessoas; equilíbrio entre o amor e a razão; dar oportunidade de crescimento a todos os colaboradores da organização; por intermédio de informações compartilhadas, obter o comprometimento da equipe; mediante organizado esforço, atingir os objetivos organizacionais, sem deixar de satisfazer às necessidades das pessoas.

Ao também fazer a conexão holística, Chang (2001) descortinou uma visão do processo de gerir pessoas por intermédio do comprometimento organizacional, no qual os elementos que estão

Revista Ibero-Americana de Estratégia - RIAE, São Paulo, v. 9, n. 1, p. 32-55, jan./abr. 2010. 
envolvidos e, simultaneamente, são determinantes desse processo, são constituídos de linearidade e não linearidade, numa abordagem sistemicamente complementar e geradora da efetividade nos resultados individuais e organizacionais.

Ainda na linha holística, ao fazer uma incursão pela subjetividade na gestão com pessoas, Davel e Vergara (2001) associaram o pensar, o sentir e o expressar nas organizações, por meio de questões simultâneas acerca de cognição, interioridade, prazer, emoção, relações amorosas e familiares, culturas, inovação e poder, agindo e interagindo nas organizações.

A gestão de pessoas atrelada à importância que o comportamento humano tem assumido foi vista por Fischer (2002), indicando que, quando o conceito do modelo de gestão de pessoas era estrategicamente orientado, sua missão prioritária passava a consistir-se em identificar padrões de comportamento coerentes com o negócio da organização. A partir de então, obter tais padrões, mantê-los, modificá-los e associá-los aos demais fatores organizacionais passaria a ser o objetivo principal.

Contudo, Dutra (2002) assinalou as bases movediças em que estavam assentados os conceitos e instrumentos de gestão de pessoas, gerando, nas pessoas, dificuldade de localizar-se na organização, de avaliar com clareza suas perspectivas e de estabelecer um projeto profissional em linha com as expectativas e necessidades organizacionais. Enfatizou, ainda, que o modelo de gestão de pessoas necessitava ser exigente de oferta de suporte ao desenvolvimento mútuo da organização e das pessoas nela inseridas.

\section{A ESTRATÉGIA DE MUDANÇA ORGANIZACIONAL}

Mudança é um termo utilizado pelas organizações, com a força necessária para o cuidado com a sobrevivência e, a cada dia, cresce o esforço para que esse cuidado extrapole os limites do básico. É assumido neste artigo o conceito de mudança organizacional de Fischer e Lima (2005), no qual ela é entendida como qualquer intervenção realizada na organização, com o objetivo de alterar seus elementos-chave (estratégia, natureza do trabalho, pessoas, estrutura informal e formal, sistemas, processos, métodos e procedimentos). Nesse conceito, a mudança organizacional pode exercer influência nos diversos subsistemas da organização, pode impactar todos os membros da organização e seus comportamentos no trabalho e, também, derivar mudanças nos resultados da organização.

Revista Ibero-Americana de Estratégia - RIAE, São Paulo, v. 9, n. 1, p. 32-55, jan./abr. 2010. 
A Estratégia de Gestão de Pessoas como Ferramenta do Desenvolvimento Organizacional

Sob tal perspectiva, compreender o significado da gestão estratégica de pessoas pode corresponder ao ato de destituir a despersonalização nas relações entre as pessoas, da categoria de consequência mais grave e mais danosa de um modelo mecanicista e reducionista, com o qual as organizações foram projetadas e administradas ao longo de tantas décadas. Isso implica dizer que, quando as organizações passam por transformações, os executivos de recursos humanos as ajudam a identificar um processo para administrarem a mudança (Leite \& Albuquerque, 2009; Ulrich, 1998).

Nesse processo, a influência dos ambientes psicossociais, com ênfase na importância do desenvolvimento do ser humano e das relações interpessoais, representando possibilidades de caminhos para o desenvolvimento organizacional, foi elucidada por Biehl (2004). Também MacGregor (1950 como citado em Bennis, 1972), já preconizava o fim da antiga concepção de que as pessoas fariam todo o trabalho do mundo somente se fossem forçadas a fazê-lo, por meio de ameaças ou de intimidação ou pelos camuflados métodos autoritários do paternalismo.

Pelo contrário, a dimensão interpessoal não pode ser ignorada e, notadamente, de acordo com Dutra (2004), o processo de valorização das pessoas deve ser mediado pelas recompensas por elas recebidas, como contrapartida de seu trabalho para a organização; contrapartida essa entendida como atendimento às expectativas e necessidades dessas pessoas. $\mathrm{O}$ autor considerou que um sistema de gestão de pessoas, integrado e estratégico, resultaria em maior sinergia entre suas partes e faria com que os vários processos de gestão do sistema se reforçassem mutuamente, o que garantiria a esse sistema maior efetividade, coerência e consistência.

No mundo contemporâneo, essa dimensão interpessoal é visível e marcante em todas as organizações. Vale enfatizar, reiteradamente, que as relações interpessoais são tão ou mais importantes do que a qualificação individual para as tarefas. Rogers (1977) sugeriu que se o gestor pudesse ajudar a criar um clima que se caracterizasse pela autenticidade, pelo apreço e pela compreensão, pessoas e grupos conseguiriam sair: da rigidez e caminhar em direção à flexibilidade; da vivência estática à vivência processual; da dependência à autonomia; do previsível a uma criatividade imprevisível; da defensividade à autoaceitação; da acomodação à apresentação de uma prova vívida de uma tendência à realização.

O autor ainda enfatizou que, se os indivíduos se relacionassem de maneira harmoniosa, com simpatia e afeto, as probabilidades de colaboração poderiam aumentar, a sinergia poderia ser atingida e resultados produtivos surgiriam de modo consistente. Assim, esses indivíduos poderiam exercitar, de maneira simples e direta, o início e a manutenção do processo de administração de seus conflitos, protegidos pela confiança e pela possibilidade de contar com a colaboração de todos, revelando suas dificuldades, frustrações e anseios.

Revista Ibero-Americana de Estratégia - RIAE, São Paulo, v. 9, n. 1, p. 32-55, jan./abr. 2010. 
Se, por outro lado, eles se relacionassem com defensividade, Argyris (1992) alerta para a necessidade de serem enfrentadas as defesas organizacionais, responsáveis pela produção do cinismo, da impotência, do distanciamento, do desempenho medíocre, da aprendizagem deficiente e da consequente falta de comprometimento organizacional.

Ressaltando-se aspectos de mudança, relembre-se que, em estudo de tendências em gestão de pessoas em organizações brasileiras, Fischer e Albuquerque (2004) salientaram que entre as dez estratégias listadas no conjunto de categorias de estratégias, apontado pela pesquisa, encontra- se a estratégia de investir no estímulo ao comprometimento das pessoas com os objetivos organizacionais. Tal estratégia seria a que os profissionais de gestão de pessoas adotariam para superar os desafios.

Bastante elucidados, os desafios da evolução do conceito de gestão de pessoas, por meio da mudança da estratégia de controle para a estratégia do comprometimento, sugerem, em última instância, uma deliberação de mudança, em nível comportamental nas organizações, de acordo com Albuquerque (1999), alinhado a Walton (1997). Walton deixou claro que, na estratégia de controle há pouca definição de políticas em relação à voz do funcionário, uma vez que o pressuposto desse modelo é de baixo comprometimento do funcionário. Esse autor reiterou que, na estratégia de comprometimento, deveriam ser esperadas mudanças nas responsabilidades individuais, desde que as condições mudassem e, as equipes, não os indivíduos, fossem as unidades organizacionais responsáveis pelo desempenho.

Conforme mostrado por Coutinho e Kallás (2005), as organizações têm evoluído de um processo decisório autoritário-paternalista para um consensual-participativo. Entretanto, afirmaram eles, somente aquelas que já ultrapassaram os limites do consenso estavam alimentando uma cultura preparada para a mudança, assegurando participação, voz e veto para todos os que se interessam pela questão do processo decisório.

Esses autores alinharam-se a Rogers (1977), a Argyris (1992), a Walton (1997) e a Albuquerque (1999), ao considerarem que uma organização capaz de adaptar sua cultura às demandas estratégicas seria também capaz de: aceitar os erros honestos; estimular e manter condições para elevar a autoestima das pessoas; praticar um processo decisório que, efetivamente, garantisse a participação, voz e veto a todos os envolvidos nas escolhas específicas. Dessa forma, a estratégia de controle, na gestão de pessoas, não atenderia ao requisito do desenvolvimento, razão pela qual práticos e estudiosos da administração vêm se debruçando sobre a problemática que envolve as pessoas no cotidiano das organizações.

Para que haja mudança organizacional, todavia, Albuquerque (2002) afirmou ser a administração estratégica um processo amplo que permite à organização procurar atingir o seu

Revista Ibero-Americana de Estratégia - RIAE, São Paulo, v. 9, n. 1, p. 32-55, jan./abr. 2010. 
A Estratégia de Gestão de Pessoas como Ferramenta do Desenvolvimento Organizacional

propósito ao longo do tempo, abrangendo a visão, a formulação e a implementação, bem como o feedback contínuo e a avaliação dos resultados, com vistas a orientar e empreender as ações organizacionais de natureza estratégica, tática e operacional. Sua afirmação encontra-se em linha com Fischmann (1987), quando afirmou que o sucesso da estratégia organizacional dependia do desempenho de duas atividades básicas: a formulação e a implementação estratégica.

Relembre-se, nessa linha, que: a administração estratégica envolve funções administrativas tais como planejar, organizar, dirigir e controlar no nível estratégico da organização, preocupandose em capacitá-la para que seja possível mudar a atitude das pessoas de decisão (Fischmann \& Almeida, 1990); a estrutura organizacional decorre de sua estratégia de crescimento e, cada mudança estratégica deve ser acompanhada de uma mudança estrutural que a apoie (Chandler, 1962); a administração estratégica consiste em decisões e ações administrativas que auxiliam a assegurar que a organização formule e mantenha adaptações benéficas com seu ambiente (Wright et al., 1998); as decisões estratégicas se diferenciam das demais decisões organizacionais pela amplitude, frequência e importância (Kleindorfer, Kunreuther \& Schoemaker, 1993); intervir, pois, significa entrar, estrategicamente, nos variados subsistemas da organização ou nas relações entre as pessoas, com o propósito de ajudar na melhoria da eficácia organizacional.

\section{O DESENVOLVIMENTO ORGANIZACIONAL}

A concepção de desenvolvimento organizacional ainda desfruta sua recente maturidade, pois somente depois de 1960 ela se fez registrar. Carece, portanto de novas pesquisas para continuar a amadurecer. Os pressupostos teóricos que embasam a sua filosofia e as suas técnicas são os mesmos para Estados Unidos, Europa e Brasil, não obstante contextos socioculturais e históricos diferentes.

Longe de ser somente uma técnica, o desenvolvimento organizacional é um processo contínuo, implica necessidade de mudança, exige planejamento, promove melhoria de eficiência e eficácia e assegura a efetividade da organização. Tal concepção se realiza com o envolvimento de todos os escalões da organização, iniciando-se pelo mais alto e verticalizando-se, sempre com o apoio desse mesmo escalão. É decorrente de um diagnóstico específico da própria organização e pode utilizar vários tipos de intervenção.

Essas ideias encontram respaldo no trabalho de Beckhard (1969), no qual o desenvolvimento organizacional é visto como um esforço planejado que abrange toda a organização, administrado do alto para aumentar a eficiência e a saúde da organização, por intermédio de intervenções planejadas

Revista Ibero-Americana de Estratégia - RIAE, São Paulo, v. 9, n. 1, p. 32-55, jan./abr. 2010. 
nos procedimentos da organização e de conhecimentos fornecidos pelas ciências do comportamento.

Com base nessa visão, o desenvolvimento organizacional envolve: um diagnóstico sistemático da organização, a formulação de um plano estratégico de melhoria e a mobilização de recursos para levar a cabo o esforço; o sistema total; a alta administração do sistema; o delineamento para se compreender as metas do desenvolvimento organizacional em termos de eficiência, eficácia e efetividade.

No que tange ao plano estratégico de melhoria, faz-se necessário relembrar o que foi alertado por Mintzberg (1991), de que a estratégia como um plano representava a direção, o curso conscientemente definido para a organização seguir no futuro. Em 2004, Mintzberg reiterou que planejamento significava análise, enquanto estratégia significava síntese, e reenfatizou o importante papel que o planejamento estratégico tinha a desempenhar nas organizações, quando combinado com os apropriados contextos. Desse modo, todos os demais fatores elucidados na visão de Beckhard (1969) ganharam reforço e espaço para reflexão e balizamento.

Em linha com a ideia de intervenções planejadas, Schein (1992) trouxe, no campo de ajuda externa, o desenvolvimento organizacional como um conjunto de atividades desenvolvidas pelo consultor, em parceria com o cliente, de modo a facilitar a percepção, o entendimento e a ação sobre fatos inter-relacionados que ocorriam no ambiente das organizações.

A realização de um processo de desenvolvimento organizacional, entretanto, não deve pretender solucionar problemas específicos, isolados, rotineiros ou eventuais em caráter emergencial, apresentando resultados imediatos ou em curto espaço de tempo. Deve compreender um processo de mudança envolvendo toda a organização, com o objetivo de melhorar sensivelmente seu desempenho. Isso foi corroborado por Bennis (1972), quando afirmou que o desenvolvimento organizacional se constituía em uma complexa estratégia educacional voltada para mudar crenças, atitudes, valores e estrutura de organizações, de tal modo que elas pudessem melhor se adaptar a novos mercados, tecnologias, desafios e ao próprio ritmo de mudança. O autor reforçou, ainda, que o desenvolvimento organizacional seria necessário sempre que as instituições sociais concorressem e lutassem pela sobrevivência, sob condições de mudança crônica.

Lawrence e Lorsch (1972) trataram o desenvolvimento organizacional como modificação que conduziria a um melhor ajustamento entre a organização e as demandas do seu ambiente e/ou a um melhor ajustamento entre a organização e as necessidades dos contribuintes individuais. Já Zaltman e Duncan (1977) o trataram como processo de reaprendizado do indivíduo ou grupo em resposta a novos requerimentos percebidos de uma determinada situação, exigindo ação e

Revista Ibero-Americana de Estratégia - RIAE, São Paulo, v. 9, n. 1, p. 32-55, jan./abr. 2010. 
A Estratégia de Gestão de Pessoas como Ferramenta do Desenvolvimento Organizacional

resultando em mudança na estrutura e/ou funcionamento de sistemas sociais. Robbins (1999) o considerou como termo usado para compreender um conjunto de intervenções de mudança planejada construídas sobre valores democrático-humanistas que buscassem aprimorar a eficácia organizacional e o bem-estar do empregado.

Usualmente, para representar o processo de desenvolvimento organizacional, recorre-se a quatro etapas: diagnóstico, responsável pela geração de informações sobre as causas do problema, as mudanças que devem ocorrer para que tal problema seja resolvido e os resultados esperados dessas mudanças; plano de ação, compreendido como capaz de estabelecer a estratégia de intervenção para que as mudanças sejam efetivadas, incluindo participação, envolvimento e comprometimento de pessoas-chave no processo e os métodos a serem aplicados; intervenção, no sentido da execução do plano aprovado e utilização de métodos sistemáticos de mudança comportamental; avaliação e controle, englobando a coleta de dados que permitem comparar a situação anterior com a situação pós-intervenção.

\section{AS INTERAÇÕES DINÂMICAS ENTRE ESTRATÉGIA DE GESTÃo DE PESSOAS, ESTRATÉGIA DE MUDANÇA ORGANIZACIONAL E DESENVOLVIMENTO ORGANIZACIONAL}

As interações dinâmicas entre estratégia de gestão de pessoas, estratégia de mudança organizacional e desenvolvimento organizacional ocorrem naturalmente e é perceptível o modo como os três pontos estão imbricados. Ao falar sobre as características das decisões estratégicas, por exemplo, Wright, Kroll e Parnell (2007) afirmaram que elas requereriam comprometimento. Tais interações implicam decisões estratégicas que requerem comprometimento.

O alerta dado por Chatterjee (2006) de que os objetivos do nível de topo da organização precisariam ser traduzidos em objetivos de nível funcional, que, por sua vez, deveriam ser desenvolvidos nos níveis mais baixos, de forma a maximizar o reforço dos objetivos do nível mais alto, deixa clara a necessidade de pensar e agir sistêmica e compartilhadamente. Note-se que, novamente, trata-se de decisões estratégicas requerendo comprometimento.

Tais ideias encontraram respaldo em MacGregor (1980) que, no papel de consultor e instigando o aprofundamento de aspectos comportamentais na mudança, desde 1967, criou um instrumento de desenvolvimento de equipes, no qual o pressuposto básico era o processo de mudança planejada, envolvendo confiança recíproca, comunicações, apoio recíproco, objetivos, habilidades, controle e ambiente, cujos resultados implicavam prática de feedback entre os membros

Revista Ibero-Americana de Estratégia - RIAE, São Paulo, v. 9, n. 1, p. 32-55, jan./abr. 2010. 
da equipe organizacional, o que representou um estupendo incremento no processo de mudança de cultura nas organizações.

Da mesma maneira que, nos anos 70, Argyris e Schön (1974-1977) contribuíram para a compreensão de que o desenvolvimento organizacional estaria associado aos critérios de competência: autoaceitação, essencialidade, confirmação, capacidade de investigação, coesão grupal, interdependência, cooperação, respeito à individualidade, respeito à confiança recíproca, respeito ao comprometimento interno, alinhamento aos objetivos das lideranças influenciado na base da competência e não do poder formal e sucesso psicológico nos níveis individual, grupal, intergrupal e organizacional. Eles reiteraram a condição de processo em que o desenvolvimento organizacional necessitaria estar pautado, cujo caráter de longo prazo não poderia ser negligenciado.

Esses autores facilitaram o entendimento de que o desenvolvimento organizacional somente poderia ser iniciado quando houvesse a compreensão clara das situações que facilitam ou obstam a transformação, quais sejam: se os gestores valorizarem o processo, as pessoas tenderão a sentir-se sólidas e eficazes, promovendo a multiplicação; se tais gestores encontrarem-se divididos, essas pessoas tenderão a conhecer as limitações e ficarão à mercê do aproveitamento inteligente das brechas; se a cúpula se apresentar desunida e alheia ao cotidiano organizacional, as equipes tenderão a sentir-se incapazes, incorrendo no risco da dissolução. Observe-se, outra vez, a necessidade de serem tomadas decisões estratégicas requerendo-se comprometimento.

Nesse sentido, Burke e Hornstein (1972) reforçaram o que foi elucidado por Bennis (1972). Os autores chamaram a atenção para a cultura vigente dentro da organização - sem a qual o desenvolvimento organizacional poderia tender à inocuidade - e reiteraram a noção de processo contínuo que demandaria tempo para ser implementado.

No Brasil, quando Souza (1975) trouxe a público casos e instrumentos de desenvolvimento organizacional, indubitavelmente, contribuiu com a percepção de que, como referenciais, eles prescindiriam da visão do interventor, de modo a impedir que fossem usados como sinônimo de treinamento, o qual poderia ou não ser utilizado como instrumento de intervenção. Como tal, há de ser sempre com a perspectiva de ação contínua, compartilhada, sistêmica e de longo prazo.

Incrementando ainda o estudo acerca do desenvolvimento organizacional no Brasil, Foguel \& Souza (1985) contribuíram com a reflexão de que desenvolvimento implicaria mudança, mas nem todo tipo de mudança traduziria ou seria reflexo de desenvolvimento. Por sua vez, desenvolvimento não seria sinônimo de movimento contínuo e uniforme ao longo do tempo. Nessa linha, tomando-se por base Abbagnano (2003), relembra-se que os filósofos e sociólogos utilizaram o

Revista Ibero-Americana de Estratégia - RIAE, São Paulo, v. 9, n. 1, p. 32-55, jan./abr. 2010. 
A Estratégia de Gestão de Pessoas como Ferramenta do Desenvolvimento Organizacional

termo mudança, em geral, significando movimento ou processo de qualquer espécie; o princípio lógico da transformação, consistindo em possibilidades. Não obstante a expressão desenvolvimento ter precedentes no conceito aristotélico de movimento em direção ao melhor, seu significado estaria estreitamente ligado ao conceito de progresso e seu sinônimo mais próximo seria evolução.

As interações dinâmicas entre estratégia de gestão de pessoas, estratégia de mudança organizacional e desenvolvimento organizacional, portanto, novamente podem ser vistas ao tomarse por base o que Wright et al. (2007) alertaram, ou seja: o fato de sempre que houver uma mudança na estratégia, torna-se imperativo observar as possíveis necessidades de mudança na cultura organizacional para conseguir evolução na implementação estratégica.

\section{OS ASPECTOS METODOLÓGICOS}

O presente estudo caracteriza-se como exploratório, visto que pretendeu investigar como ocorrem as interações dinâmicas entre estratégia de gestão de pessoas, estratégia de mudança organizacional e desenvolvimento organizacional em uma organização multinacional do segmento de carbono e grafita, aqui denominada de OM, por meio da descrição e análise desse processo, implementado pela via da gestão estratégica de pessoas.

Optou-se pela abordagem qualitativa, com a utilização do método de estudo de caso, pois a adoção dessa estratégia de investigação demonstrou-se coerente, uma vez que focou um fenômeno contemporâneo dentro de seu contexto real (Yin, 2005), além de ter buscado explorar e explicar as interações dinâmicas existentes entre as variáveis que compuseram o estudo.

Coletaram-se os dados primários por meio de realização de entrevistas com roteiro semiestruturado, envolvendo-se, nessa coleta, cinco pessoas do grupo de topo, seis do gerencial, quatro do marketing/comercial, quatro do staff e sete representantes dos grupos operacionais e administrativos, constituindo-se, posteriormente, cinco grupos de foco. Os dados secundários foram levantados dos documentos fornecidos pela organização.

A interpretação dos dados primários se deu a partir da análise de conteúdo. Tal análise consistiu em categorizar, classificar e codificar os conteúdos (Bardin, 1977) para interpretá-los no decorrer do processo de tratamento dos dados, considerando-se dimensões e critérios de análise distintos para cada fonte de evidência, a saber: o conteúdo das entrevistas, dos documentos, das discussões dos grupos focais e do referencial teórico de fundamentação da pesquisa.

$\mathrm{O}$ processo total de interpretação dos dados compreendeu as seguintes dimensões: 
entrevistas semiestruturadas (Bardin, 1977; Krippendorff, 1986; Vergara, 2005); discussões objetivas e não estruturadas (Krueger, 1994; Parasuraman, 1986) nos grupos de foco; documentos organizacionais, cuja interpretação dos conteúdos foi pautada na seleção de documentos cujos registros retrataram e/ou evidenciaram a ocorrência do fenômeno investigado e/ou mudanças ocasionadas por esse fenômeno.

\section{O ESTUDO DE CASO}

A OM é uma organização multinacional voltada para o desenvolvimento e a produção de produtos de carbono e grafita. Sua matriz é americana, com unidades localizadas em vários países. Este estudo de caso foi desenvolvido na unidade do Brasil, cuja base da estratégia de desenvolvimento se reflete na seguinte afirmação:

"Nossa organização desenvolveu rotinas defensivas que se tornaram padrões aceitáveis de conduta ao longo desses anos. E é preciso mudar para desenvolvermos."

Na última década e meia essa unidade brasileira vem passando por um processo de reestruturação e tem sido vista como referência pela OM mundial:

“As rotinas defensivas já podem ser enxergadas como padrões não aceitáveis de conduta na unidade brasileira de nossa organização. Os relatórios nos mostram que pode ser valorizada a mudança a partir de cada indivíduo dessa unidade."

Todo esse processo foi iniciado pelo presidente no Brasil e vem sendo sustentado pelos diretores e gerentes. Ultimamente, eles têm se defrontado com a necessidade de desenvolver a organização, o que tem sido apoiado pela diretoria de recursos humanos, ampliada recentemente. Especialistas em desenvolvimento organizacional (Schein, 1992; Argyris, 1992; Bennis, 1972; Lawrence \& Lorsch, 1972; Beckhard, 1969; Lewin, 1935) salientaram que as estruturas convencionais de organizações não tinham condições de estimular a atividade inovadora nem de se adaptarem a circunstâncias em mudança.

Foram enfatizadas, por esses especialistas, questões críticas a essas estruturas, como: o poder da administração frustra e aliena o empregado; a divisão do trabalho e fragmentação de funções impedem o compromisso emocional do empregado com a organização; a autoridade única

Revista Ibero-Americana de Estratégia - RIAE, São Paulo, v. 9, n. 1, p. 32-55, jan./abr. 2010. 
A Estratégia de Gestão de Pessoas como Ferramenta do Desenvolvimento Organizacional

ou unidade de comando restringe a comunicação do empregado, afetando negativamente o seu comprometimento com a organização; as funções permanentes, uma vez designadas, tornam-se fixas e imutáveis. Nessa organização, a maioria dessas críticas ressoava entre os seus integrantes.

Auxiliados pela diretoria de recursos humanos, o presidente, os diretores e os gerentes da OM Brasil conseguiram levantar, junto às equipes organizacionais, um mapa no qual alguns elementos foram vistos como restritivos ao processo de desenvolvimento, corroborando as críticas dos especialistas em desenvolvimento organizacional. Outros elementos, vistos como impulsionadores, confirmaram as possibilidades de desenvolvimento da organização, na visão desses gestores agentes de mudança.

A partir de então eles passaram a lançar mão de recursos validados, para representar o processo de desenvolvimento organizacional, na OM Brasil, em quatro etapas: diagnóstico, responsável por sugerir as mudanças que deveriam ocorrer e os resultados esperados dessas mudanças, com o auxílio de profissionais externos, incluindo participação, envolvimento e comprometimento de pessoas-chave no processo; intervenção, com utilização de métodos sistemáticos de mudança comportamental, sob a responsabilidade do presidente e da diretoria de recursos humanos; avaliação e controle, englobando a coleta de dados que permitiriam comparar a situação anterior com a situação pós-intervenção.

Assim, buscando-se compreender as relações entre estratégia de gestão de pessoas, estratégia de mudança e desenvolvimento organizacional, no sentido de explicar a interação dinâmica ocorrida no fenômeno de desenvolvimento dessa unidade da organização OM, fez-se a análise documental, do processo em desenvolvimento, do conteúdo das entrevistas, das discussões dos grupos focais e do referencial teórico de fundamentação da pesquisa.

Nessa interação dinâmica foram obtidos os seguintes fragmentos de mensagens, categorizados como restritivos ao processo:

“A motivação interna é relegada a um plano inferior e predominam as motivações extrínsecas aos indivíduos, pressionados, dessa forma, a darem mais de si mesmos, sem atenção ao que eles estão sentindo;

A expressão dos medos, das vontades, das crenças, valores e sentimentos entre líderes e liderados ainda é uma ponte a ser cruzada;

Ainda vigoram os jogos de poder e controle nessa organização;

Revista Ibero-Americana de Estratégia - RIAE, São Paulo, v. 9, n. 1, p. 32-55, jan./abr. 2010. 
O movimento de definir papéis (líderes e liderados) na busca dos objetivos ainda é o forte dessa organização, em detrimento do comprometimento conjunto que possa ser obtido;

Falta à organização, para que se agregue na aprendizagem, o exercício dos diferentes papéis para ajudar na mudança. O conhecimento, a informação e a comunicação são mais valorizados que a aprendizagem e não significam mudança;

Falta aos membros dessa organização habilidade de mudar e perceber o mundo como é hoje."

Juntamente com essa categorização dos fragmentos restritivos puderam ser levantados dados documentais, em que o plano de ação para a mudança contemplava: envolvimento de toda a organização para que a mudança pudesse ocorrer efetivamente; orientação sistêmica voltada para as interações entre as várias partes da organização que se influenciam reciprocamente e para as relações de trabalho entre pessoas, bem como para as estruturas e os processos organizacionais; utilização de vários agentes de mudança, pessoas que desempenham os papéis de estimular e coordenar a mudança dentro de cada um dos departamentos da organização; provimento de informações de retorno aos participantes das equipes para que eles tivessem dados concretos que fundamentassem suas decisões.

Do mesmo modo, foram obtidos fragmentos de mensagens, categorizados como impulsionadores para o processo:

“O pressuposto fundamental da adoção dos padrões éticos para granjear o respeito das pessoas e da organização já é um dado observável aqui no nosso cotidiano;

Apreciações e feedbacks individuais e grupais já podem ser incorporados às práticas desta organização, por consentimento dos envolvidos;

Já se delineia a visão de que a cultura integrativa, orientada para atrair, manter e reter pessoas talentosas exige, desta organização, alta preocupação com as pessoas e forte expectativa sobre o desempenho;

Revista Ibero-Americana de Estratégia - RIAE, São Paulo, v. 9, n. 1, p. 32-55, jan./abr. 2010. 
A Estratégia de Gestão de Pessoas como Ferramenta do Desenvolvimento Organizacional

É clara a percepção de que a força da cultura influencia a intensidade do comportamento dos integrantes desta organização;

Existe a clareza de que não é fácil mudar a cultura desta organização. Existe a percepção de que tal cultura necessita ser olhada como algo a ser aprendido em todos os nossos níveis hierárquicos;

Já existe a consciência de que os jogos de poder podem ser desmontados, bem como pode ser incrementado o poder compartilhado por todos nós;

Há clareza de que o conteúdo da cultura vai além das relações humanas. Há a compreensão de que a cultura mais forte não é, necessariamente, a melhor para esta organização.”

Buscando-se, a partir da análise desses fragmentos, bem como de documentos, responder à questão de como a estratégia de gestão de pessoas pode ser utilizada como ferramenta para o desenvolvimento organizacional, pode-se dizer que, nessa organização, existe um esforço empreendido para tratar o que Vergara (2003) salientou como a gestão de pessoas tratada na abordagem holística, possibilitando revelar, em consequência, as interconexões das diferentes áreas do conhecimento e com o cotidiano da vida, no qual os processos integrados conduzem ao compartilhamento do poder.

Saliente-se que as interações dinâmicas entre estratégia de gestão de pessoas, estratégia de mudança e desenvolvimento organizacional dessa unidade da organização OM reforçam a fundamentação teórica deste artigo, observando-se, também, o reconhecimento da necessidade de serem tomadas decisões estratégicas requerendo-se comprometimento dos envolvidos no processo da OM Brasil.

Entretanto, para a perpetuação de tais interações, percebeu-se a necessidade de criar novos padrões de comportamento. Percebe-se também que a estratégia de gestão de pessoas nessa unidade da OM está se transformando em um processo reflexivo que gera mudança organizacional e o desenvolvimento organizacional vem ocorrendo, gradualmente, em virtude dessa transformação.

Revista Ibero-Americana de Estratégia - RIAE, São Paulo, v. 9, n. 1, p. 32-55, jan./abr. 2010. 


\section{CONSIDERAÇÕES FINAIS}

Observou-se que as interações entre estratégia de gestão de pessoas, estratégia de mudança e desenvolvimento organizacional propiciaram, à unidade brasileira da OM, a percepção clara de que a cultura organizacional não é estática e permanente, podendo sofrer alterações, dependendo de condições internas ou externas. De igual forma, a descoberta de que a única maneira viável de mudar a organização é mudar os sistemas dentro dos quais as pessoas vivem e trabalham, assim como o seu meio interno, a atmosfera psicológica intimamente ligada ao moral e à satisfação das necessidades humanas dos seus integrantes.

O processo de mudança organizacional foi iniciado, nessa unidade, a partir de forças endógenas à organização, as quais criaram a necessidade de mudança estrutural e comportamental provinda da tensão organizacional - tensão nas atividades, interações, sentimentos ou resultados de desempenho no trabalho. Tal fato corroborou a máxima dos estudiosos, de que o desenvolvimento organizacional se faz necessário sempre que a organização concorra e lute pela sobrevivência em condições de mudança.

O processo de desenvolvimento organizacional foi possível de ser implementado, nessa unidade, porque, sistematicamente, os responsáveis pela mudança delinearam modelos explícitos do que a organização deveria ser em comparação com o que era. Assim, aqueles cujas ações seriam afetadas pelo desenvolvimento sistemático estudaram, avaliaram e criticaram o modelo de mudança, para recomendar alterações, tomando por base seu próprio discernimento e compreensão. Consequentemente, as mudanças resultantes traduziram-se por apoio e não por resistências ou ressentimentos.

Verificou-se, portanto, a partir da análise de conteúdo das entrevistas e dos grupos focais, que a estratégia de gestão de pessoas pôde ser utilizada como instrumento de desenvolvimento organizacional na unidade brasileira da organização investigada.

Acredita-se que esta pesquisa contribuiu para um melhor entendimento das interações entre estratégia de gestão de pessoas, estratégia de mudança e desenvolvimento organizacional no processo de desenvolvimento dessa unidade da OM.

Contudo, por se tratar de um estudo de caso, suas análises ficam limitadas à unidade investigada, e seus resultados não podem ser generalizados. Por outro lado, eles podem ajudar no entendimento de fenômenos similares em outras unidades dessa organização e/ou outras organizações e, podem, ainda, inspirar a realização de futuras pesquisas.

Revista Ibero-Americana de Estratégia - RIAE, São Paulo, v. 9, n. 1, p. 32-55, jan./abr. 2010. 
A Estratégia de Gestão de Pessoas como Ferramenta do Desenvolvimento Organizacional

Considere-se que não há uma estratégia ideal para o desenvolvimento organizacional. Há modelos e estratégias mais ou menos adequados para determinadas situações ou problemas, em face das variáveis envolvidas e do diagnóstico efetuado. Da mesma forma, a organização é, em si, um subsistema em um ambiente que consiste em muitos outros sistemas, todos dinamicamente interdependentes. Sugere-se, por exemplo, a ampliação deste estudo junto a outras organizações que estejam passando por processos semelhantes, quer pelo método de estudo de casos múltiplos, quer pelo método de pesquisa quantitativa mais abrangente.

\section{REFERÊNCIAS}

Abbagnano, N. (2003). Dicionário de filosofia. São Paulo: Martins Fontes.

Albuquerque, L. G. (1987). O papel estratégico de recursos humanos. Tese de livre docência. São Paulo: Departamento de Administração da Faculdade de Economia, Administração e Contabilidade da Universidade de São Paulo, São Paulo, Brasil.

Albuquerque, L. G. (1999). Estratégias de recursos humanos e competitividade. In: Vieira, M. M. F.; Oliveira, L.M.B. (Orgs.) Administração contemporânea: perspectivas e estratégias. São Paulo: Atlas.

Albuquerque, L. G. (2002). A gestão estratégica de pessoas. In: Fleury, M. T. L (Org.). As pessoas na organização. São Paulo: Editora Gente.

Argyris, C. (1992). Enfrentando defesas empresariais. Rio de Janeiro: Campus.

Argyris, C. \& Shön, D. A. (1974-1977). Theory in practices: increasing professional effectiveness. San Francisco - Washington - London: Jossey-Bass Publishers.

Bardin, L. (1977). Análise de conteúdo. Portugal, Lisboa: Edições 70.

Beckhard, R. (1969). Desenvolvimento organizacional: estratégias e modelos. São Paulo: Edgard Blucher.

Bennis, W. G. (1972). Desenvolvimento organizacional: sua natureza, origens e perspectivas. São Paulo: Edgard Blucher.

Revista Ibero-Americana de Estratégia - RIAE, São Paulo, v. 9, n. 1, p. 32-55, jan./abr. 2010. 
Biehl, K. A. (2004). Grupos e equipes de trabalho: uma estratégia de gestão In: Bittencourt, C. et al. Gestão contemporânea de pessoas. São Paulo: Bookman/Artmed.

Burke, W. \& Hornstein, H. (1972). The social technology of organizational development. NTL Learning Resources Corp. Virginia, EUA: Fairfax.

Casado, T. (2007). Comportamento organizacional: fundamentos para a gestão de pessoas. In: R. C. Santos (Org.). Manual de gestão empresarial - conceitos e aplicações nas empresas brasileiras, pp. 212-233. São Paulo: Editora Atlas.

Chandler, A. D. (1962). Strategy and structure: chapters in the history of the industrial enterprise. Cambridge, MA: MIT Press.

Chang, J., Jr. (2001). Gestão de pessoas através do desenvolvimento do comprometimento organizacional: uma abordagem holística e simultânea dos determinantes envolvidos nesse processo. Tese de Doutorado, FEA/USP, São Paulo.

Chatterjee, S. (2006). Estratégias à prova de falhas. Porto Alegre: Bookman.

Coutinho, A. R. \& Kallás, D. (Org.) (2005). Gestão estratégica: experiências e lições de organizações Brasileiras. Rio de Janeiro: Campus/Elsevier.

Davel, E. \& Vergara, S. C. (Orgs) (2001). Gestão com pessoas e subjetividade. São Paulo: Editora Atlas.

Dutra, J. S. (2002). Gestão de pessoas: modelo, processos, tendências e perspectivas. São Paulo: Editora Atlas.

Dutra, J. S. (2004). Competências: conceitos e instrumentos para a gestão de pessoas na organização moderna. São Paulo: Atlas.

Fischer, A. L. (1998). A constituição do modelo competitivo de gestão de pessoas no Brasil: um estudo sobre as organizações consideradas exemplares. Tese de doutorado, FEA-USP, São Paulo, Brasil.

Fischer, A. L. (2002). Um resgate conceitual e histórico dos modelos de gestão de pessoas. In: Fleury, M. T. L. et al. As pessoas na organização. São Paulo: Editora Gente.

Fischer, A. L. \& Albuquerque, L. G. (2004). Delphi RH 2010: tendências em gestão de pessoas nas empresas brasileiras. São Paulo: PROGEP.

Fischer, H. C. R. \& Lima, S. M. V. (2005). Validação de instrumento para diagnóstico de condições facilitadoras de mudança organizacional. In: Psicologia: organizações e trabalho. Trindade: UFSC, 5, (1), 13-44.

Revista Ibero-Americana de Estratégia - RIAE, São Paulo, v. 9, n. 1, p. 32-55, jan./abr. 2010. 
A Estratégia de Gestão de Pessoas como Ferramenta do Desenvolvimento Organizacional

Fischmann, A. A. (1987). Implementação de estratégias: identificação e análise de problemas. Tese de livre docência, Universidade de São Paulo, São Paulo, Brasil.

Fischmann, A. A. \& Almeida, M. I. R. (1990). Planejamento estratégico na prática. São Paulo: Atlas.

Foguel, S. \& Souza, C. C. (1985). Desenvolvimento organizacional. São Paulo: Atlas.

Hatch, M. J. (1997). Organization theory: modern, symbolic and postmodern perspectives. New York: Oxford University Press.

Kleindorfer, P. R., Kunreuther, H. C. \& Schoemaker, P. J. H. (1993). Decision sciences - an integrative perspective. New York: Cambridge University Press.

Krippendorff, K. (1986). Content analysis: an introduction to is methodology. The Sage Commtext Series, Vol. 5. London: Prentice Hall.

Krueger, R. A. (1994). Focus group: a practical guide for applied research. Thousand Oaks: Sage Publications.

Lawrence, P. R. \& Lorsch, J. W. Lawrence, P. R. \& Lorsch, J. W. (1972). O desenvolvimento de organizações: diagnóstico e ação. São Paulo: Edgard Blucher.

Leite, N. P. \& Alburqueque, L. G. (2009). Gestão estratégica de pessoas: conceito, evolução e visão. In: Alburqueque, L.G. \& Leite, N. P. Gestão de pessoas: perspectivas estratégicas (pp. 316). São Paulo: Atlas.

Lengnick-Hall, M. L.; Lengnick-Hall, C. A.; Andrad, L. S. \& Drake, B. (2009). Strategic human resource management: the evolution of the field. Human Resource Management Review, 19 (2) 64-85.

http://dx.doi.org/10.1016/j.hrmr.2009.01.002

Lewin, K. (1935). A dynamic theory of personality. New York: Mcgraw Hill.

Macgregor, D. (1980). O lado humano da empresa. São Paulo: Martins Fontes.

Martín-Alcázar, F.; Romero-Fernández, P. M. \& Sanchez-Gardey, G. (2008). Human resource mnagement as a field of research. British Journal of Management, 19, 103-119. http://dx.doi.org/10.1111/j.1467-8551.2007.00540.x

Martín-Alcázar, F.; Romero-Fernández, P. M. \& Sanchez-Gardey, G. (2005, May). Strategic human resource management: integrating the universalistic, contingent, configurational and contextual perspectives. The International Journal of Human Resource Management, 16(5), 633-659. http://dx.doi.org/10.1080/09585190500082519

Revista Ibero-Americana de Estratégia - RIAE, São Paulo, v. 9, n. 1, p. 32-55, jan./abr. 2010. 
Marras, J. P. (2000). Administração de recursos humanos. São Paulo: Futura.

Mascarenhas, A. O. (2008). Gestão estratégica de pessoas: evolução, teoria e crítica. São Paulo: Cengage Learning.

Medeiros, J. R. (1999). O Amor Renovando o Trabalho. Rio de Janeiro: Vozes, 1999.

Mintzberg, H. (1991). Five or four strategy. In: Mintzberg H. \& Quinn J. B. The strategy process. Rio de Janeiro: Prentice-Hall do Brasil.

Mintzberg, H. (2004). Ascensão e queda do planejamento estratégico. Porto Alegre: Bookman.

Motta, F. C. P. (1972, abr./jun). Algumas considerações sobre o desenvolvimento organizacional. Revista de Administração de Empresas. Rio de Janeiro: FGV, 12(2), 34-45.

Parasuraman, A. (1986). Marketing research. Toronto: Addison-Wesley Publishing Company.

Robbins, S. P. (1999). Comportamento organizacional. Rio de Janeiro: LTC - Livros Técnicos e Científicos Editora.

Rogers, C. R. (1977). Liberdade para aprender. Belo Horizonte: Interlivros.

Schein, E. H. (1992). Organizational culture and leadership. San Francisco: Jossey-Bass.

Souza, E. L. P. (1975). Desenvolvimento organizacional: casos e instrumentos brasileiros. São Paulo: Edgard Blücher.

Ulrich, D. (1998). Os campeões de recursos humanos: inovando para obter os melhores resultados. São Paulo: Futura.

Vergara, S. C. (2003). Gestão de pessoas. São Paulo: Atlas.

Vergara, S. C. (2005). Métodos de pesquisa em administração. São Paulo: Atlas.

Walton, R. E. (1997). Do controle ao comprometimento no local de trabalho. In: Gestão de pessoas, não de pessoal (pp. 95-112). Série Harvard business review book. Rio de Janeiro: Editora Campus.

Wright, P., Kroll, M. J. \& Parnell, J. (1998). Administração estratégica: conceitos. São Paulo: Atlas.

Revista Ibero-Americana de Estratégia - RIAE, São Paulo, v. 9, n. 1, p. 32-55, jan./abr. 2010. 
A Estratégia de Gestão de Pessoas como Ferramenta do Desenvolvimento Organizacional

Wright, P., Kroll, M. J. \& Parnell, J. (2007). Administração estratégica: conceitos. São Paulo: Atlas.

Yin, R. (2005). Estudo de caso: planejamento e métodos. São Paulo: Bookman.

Zaltman, G. \& Duncan, R. (1977). Strategies for Planed Change. Nova York: Wiley-Interscience Publication.

Recebido: 30/11/2009

Aprovado: 01/02/2010

Revista Ibero-Americana de Estratégia - RIAE, São Paulo, v. 9, n. 1, p. 32-55, jan./abr. 2010. 